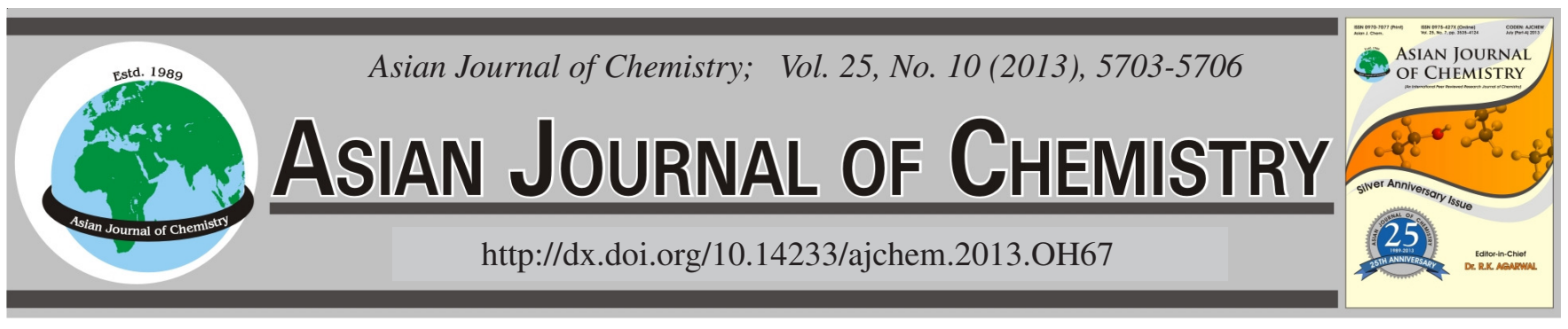

\title{
Study on Blocking and Deblocking Kinetics of Diisocyanate with $\varepsilon$-Caprolactam Using FTIR Spectroscopy $\dagger$
}

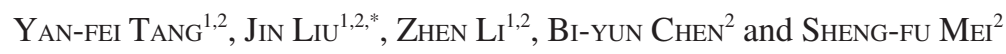

${ }^{1}$ Anhui Key Laboratory of Advanced Building Materials, Anhui University of Architecture, Hefei 230022, P.R. China

${ }^{2}$ School of Materials Science and Chemical Engineering, Anhui University of Architecture, Hefei 230022, P.R. China

*Corresponding author: E-mail: liujin@aiai.edu.cn

AJC-13310

\begin{abstract}
These blocking and deblocking reactions of toluene diisocyanate (TDI), diphenylmethane-4,4'-diisocyanate (MDI) and dicyclohexylmethylmethane-4,4'-diisocyanate (HMDI) blocked with $\varepsilon$-caprolactam were directly traced by FTIR spectroscopy at different temperatures respectively. Taking advantage of the relationship between the concentration of reactants and absorbance of NCO group according to Lambert-Beer law, the change with time for concentration was calculated under different temperatures. The results showed that the reaction rate constants for toluene diisocyanate, MDI blocked with $\varepsilon$-caprolactam were $4.05 \times 10^{-3}$ and $6.53 \times 10^{-2}$ at $60{ }^{\circ} \mathrm{C}$ respectively, while the reaction rate constant for HMDI with catalyst was $3.56 \times 10^{-3}$ at $140^{\circ} \mathrm{C}$, the class of reaction kinetics for diisocyanate (TDI and MDI) blocked with $\varepsilon$-caprolactam were first order and second order respectively and the reaction of blocked HMDI was second order reaction selecting stannous octoate as catalyst. The Arrhenius equation was employed to acquire the activation energies of blocked diisocyanate (TDI, MDI and HMDI) respectively. The process of deblocking for blocked diisocyanate was also studied by TGA and FTIR.
\end{abstract}

Key Words: Diisocyanate, $\varepsilon$-Caprolactam, Blocking and Deblocking, Reaction kinetics.

\section{INTRODUCTION}

Polyurethanes are synthetic multi-block co-polymer materials, which can be prepared through chemical reaction or polymeric processing into a series of products, like elastomers, adhesives, foams, sealants and coatings widely used in every engineering field ${ }^{1,2}$. Polyurethanes has become one of hotpots in polymer materials at present and magical polyurethanes with special function appears almost daily. Due to the high reactivity of isocyanates, polyurethanes was usually prepared by two package reaction. Two packages polyurethanes have placed an important role in application, but their usage would be limited under certain conditions, which need to be mixed just prior to the application. Blocked isocyanates have several advantages, like marked reduction of moisture sensitivity and elimination of toxicity associated with the free isocyanates. It is widely used in kinds of powder coating, elastomer and adhesive ${ }^{3}$. With the characteristic of fine particle, well-distributed, simple configuration and harmless to the environment, the industrial importance of blocked isocyanates can be clearly seen from number of patents ${ }^{4,5}$. Several compounds such as phenols, oximes, amides, imides, imidazoles, amindines, caprolactam and related compounds have been reported as blocking agents. Among these blocking agents, $\varepsilon$-caprolactam was one of the most studied blocking agents because of the stability of blocking products and $\varepsilon$-caprolactamblocked products were good crosslinking agent to improve performance of engineering materials. Many researchers ${ }^{6-10}$ have been engaged in the research of this aspect, but the blocking and deblocking kinetics of diisocyanate with $\varepsilon$-caprolactam were seldom reported.

In this paper, the reaction kinetics of toluene diisocynate, diphenylmethane-4, $4^{\prime}$-diisocyanate (MDI) and dicyclohexylmethylmethane-4,4'-diisocyanate (HMDI) blocked with $\varepsilon$ caprolactam were studied by FTIR. In addition, deblocking reaction of a series of $\varepsilon$-caprolactam-blocked products and thermodynamics of the reactions were also researched.

\section{EXPERIMENTAL}

The $\varepsilon$-caprolactam was from Sinopharm Chemical Reagent Co. Ltd., AR) and the toluene diisocynate, diphenylmethane-4,4'-diisocyanate (MDI) and dicyclohexylmethylmethane-4,4'-diisocyanate (HMDI) were supplied by ANLI Artificial Leather Co. Ltd. The solvents of toluene (AR) 
from Xilong Chemical Co. Ltd. and the acetone from Shanghai B \& C Chemical Co. Ltd. were dried by 4 A molecular sieve for $4 \mathrm{~h}$ before using.

Measurements: The process of blocking and deblocking were observed by WQF-300 FTIR. The characteristic peak of NCO from diisocyanate at $2274 \mathrm{~cm}^{-1}$ was sensitive to reaction, which was used as tracking. The absorbance of $\mathrm{C}-\mathrm{H}$ in reaction didn't vary with time, which was used as inner standard peak. The absorbance of NCO group was recorded during the reaction with the control of the data collection software. With the constant temperature heating device, the temperature controller confined the temperature to change within $5-10^{\circ} \mathrm{C}$ during the best process of blocking and deblocking. The fluctuation should be within $\pm 0.5^{\circ} \mathrm{C}$. The reaction kinetics was calculated by Lambert-Beer law using the initial concentration corresponded with initial absorbency of NCO group and the change of absorbency responded to the change of sample concentration indirectly.

TGA adopted STA409PC thermal analyzer to measure weight loss and thermal performance. The heating rate was kept at $10 \mathrm{~K} / \mathrm{min}$ and high pure $\mathrm{N}_{2}$ as shelter gas. The range of temperature was controlled from $50{ }^{\circ} \mathrm{C}$ to $400{ }^{\circ} \mathrm{C}$.

\section{RESULTS AND DISCUSSION}

Reaction Kinetics of blocked toluene diisocynate with $\boldsymbol{\varepsilon}$-caprolactam: The reaction for toluene diisocynate blocked with $\varepsilon$-caprolactam was shown in Fig. 1 . The initial concentration of $\mathrm{NCO}$ in this reaction system was $\mathrm{C}_{0}=4.72 \times 10^{-3}$ mol g ${ }^{-1}$. Fig. 2 illustrated that the change with time for the absorbance of NCO peak at $2274 \mathrm{~cm}^{-1}$. The concentration of $\mathrm{NCO}$ was figured out at every moment and defined the result of $\log \left(\mathrm{C}_{0} / \mathrm{C}\right)$ to be as the corresponding figure for time. The plots of $\log \left(\mathrm{C}_{0} / \mathrm{C}\right)$ against time for blocking reaction of toluene diisocynate with $\varepsilon$-caprolactam at different temperatures were shown in Fig. 3.

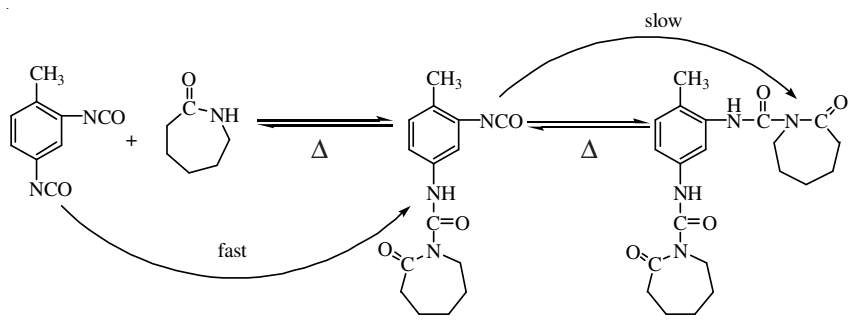

Fig. 1. Scheme of the reaction of TDI deblocked with $\varepsilon$-caprolactam

Toluene diisocynate was deblocked by $\varepsilon$-caprolactam at $60,70,80^{\circ} \mathrm{C}$ respectively. The concentration of $\varepsilon$-caprolactam was more than that of toluene diisocynate at molar 2.2:1. The absorbency of NCO group continuous became low with time in Fig. 2, which indicated that the blocking reaction was proceeding. Combining with the results of the linear relationship of $\log \left(\mathrm{C}_{0} / \mathrm{C}\right)$ against time under different temperatures shown in Fig. 3, it made clear that the class of the reaction was first order. At the beginning of the reaction, $\varepsilon$-caprolactam reacted with one NCO group from toluene diisocynate, this process was fast. As the reaction continuous, $\varepsilon$-caprolactam reacted with the other NCO group to achieve deblocked products, this process was slower. The plenty of groups of toluene diisocynate and the structure of $\varepsilon$-caprolactam similar to benzene ring lead that the steric hindrance was stronger in the blocking reaction. The reaction rate depended on second process of the blocking reaction. It was related to toluene diisocynate. The constant of reaction rate $\kappa_{1}$ was obtained from the slope listed in Table-3.

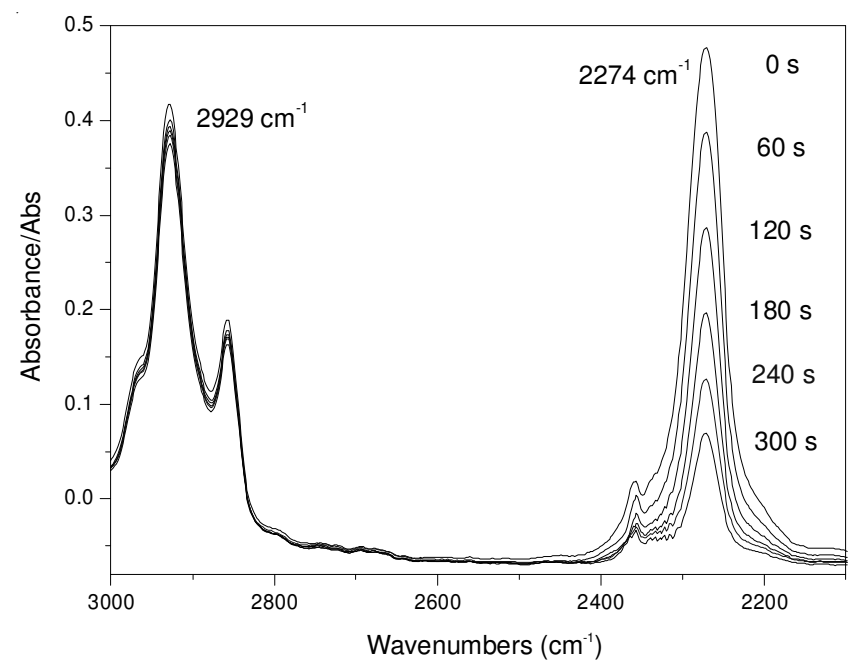

Fig. 2. FTIR curves of NCO absorption band at $60{ }^{\circ} \mathrm{C}$

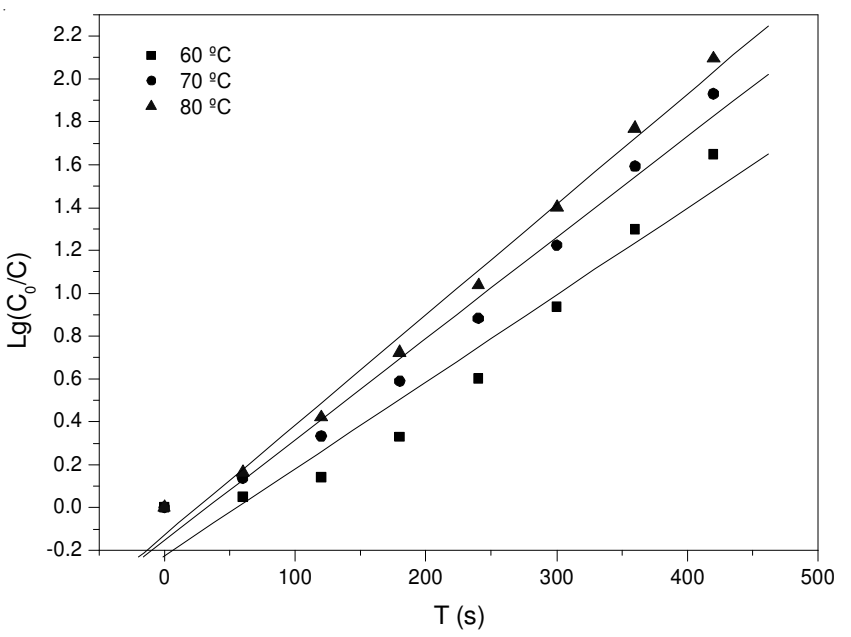

Fig. 3. Plots of $\log \left(\mathrm{C}_{0} / \mathrm{C}\right)$ against time at different temperatures

Deblocking reaction for blocked toluene diisocynate with $\varepsilon$-caprolactam: The product of the blocked toluene diisocynate was analyzed by TGA, which estimated that the deblocking reaction emerged at $160{ }^{\circ} \mathrm{C}$. This process was confirmed by FTIR.

The blocked product was dissolved by toluene and then coated on monocrystalline silicon piece. Temperature was controlled at $160{ }^{\circ} \mathrm{C}$ and $165^{\circ} \mathrm{C}$ with heating device. The change of NCO group was observed by FTIR.

The absorbance of NCO group appeared at $160^{\circ} \mathrm{C}$ during deblocking reaction shown in Fig. 5, this result was consistent with TGA. The absorbance of NCO group almost did not vary with time after $165^{\circ} \mathrm{C}$. The kinetics research for the deblocking reaction of blocked toluene diisocynate with $\varepsilon$-caprolactam had more sophisticated process and the temperature should be controlled much more accurate in range of $5^{\circ} \mathrm{C}$. 


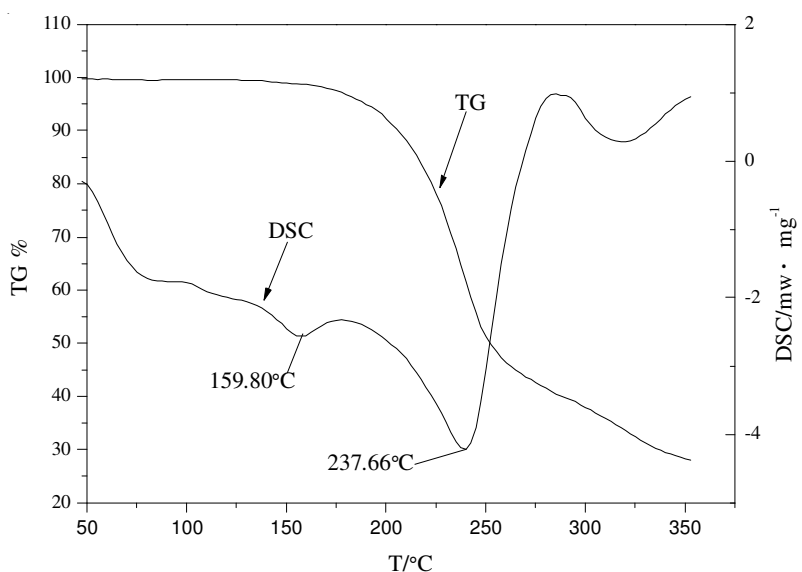

Fig. 4. TG and DSC curves of the deblocking reaction of blocked TDI

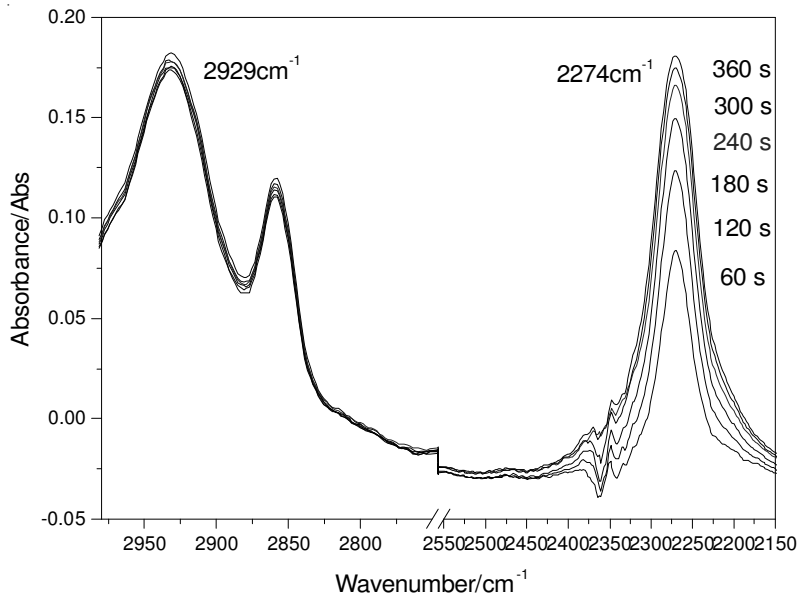

Fig. 5. FTIR curves of $\mathrm{NCO}$ absorption band with time in the deblocking reaction at $160{ }^{\circ} \mathrm{C}$

Reaction kinetics of blocked MDI with $\varepsilon$-caprolactam: The reaction of MDI blocked with $\varepsilon$-caprolactam was shown in Fig. 6. The initial concentration of NCO in this reaction system was $\mathrm{C}_{0}=4 \times 10^{-3} \mathrm{~mol} \cdot \mathrm{g}^{-1}$. Table- 1 illustrated that the absorbance peak of $\mathrm{NCO}$ at $2274 \mathrm{~cm}^{-1}$ changed with time. The concentration of $\mathrm{NCO}$ was figured out at every moment and defined the result of $\left(1 / \mathrm{C}-1 / \mathrm{C}_{0}\right)$ to be as the corresponding figure for time in Fig. 7.

\begin{tabular}{|c|c|c|c|c|c|c|c|}
\hline & & $\begin{array}{l}\text { SORB } \\
\text { DIFFE }\end{array}$ & $\begin{array}{r}\text { TAP } \\
\mathrm{CEE} O \mathrm{OF} \\
\mathrm{ENT} \mathrm{T}\end{array}$ & $\begin{array}{l}\text { E-1 } \\
\text { LOCK } \\
\text { IPERA }\end{array}$ & $\begin{array}{l}\text { D MDI } \\
\text { URES }\end{array}$ & & \\
\hline & & & & Absc & ance & & \\
\hline & & & & & & & \\
\hline Waven & $\begin{array}{l}\text { mbers } \\
\text { (1) }\end{array}$ & 2934 & 2274 & 2934 & 2274 & 2934 & 2274 \\
\hline & 30 & & 0.452 & & 0.238 & & 0.593 \\
\hline & 60 & & 0.278 & & 0.113 & & 0.216 \\
\hline lime & 90 & 0.558 & 0.176 & 0.247 & 0.047 & 0.599 & 0.066 \\
\hline & 120 & & 0.098 & & 0.009 & & 0.015 \\
\hline & 150 & & 0.073 & & 0.002 & & 0.006 \\
\hline
\end{tabular}

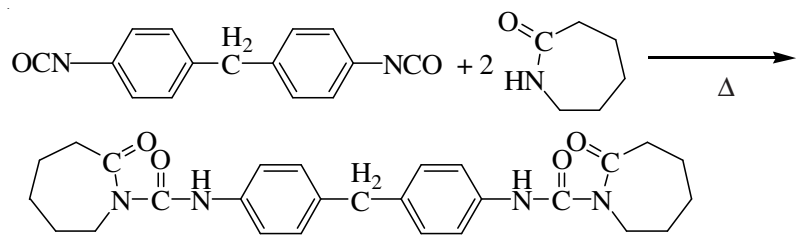

Fig. 6. Scheme of the reaction of MDI diblocked with CL

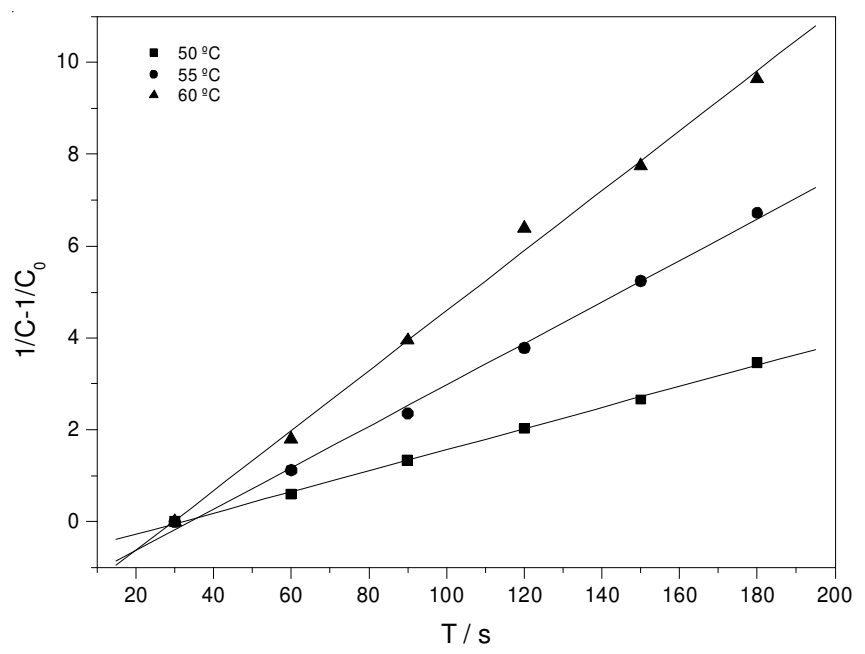

Fig. 7. Plots of $\left(1 / \mathrm{C}-1 / \mathrm{C}_{0}\right)$ against time for blocked MDI

The absorbance of NCO group which changed with time at different temperatures was shown in Table-1. The absorbance of NCO group continuously became low with time, which indicated that the blocking reaction kept proceeding. It illustrated that the blocking reaction for MDI was the second order reaction demonstrated by linear relationship under different temperatures shown in Fig.7. The steric hindrance of MDI was weak and the reactivity of MDI was so high that MDI mixed together with $\varepsilon$-caprolactam reacted quickly at $50{ }^{\circ} \mathrm{C}$, the blocking reaction was in relationship with MDI and $\varepsilon$ caprolactam. The constant of reaction rate $\kappa_{2}$ from the straight slope was listed in Table-3.

Deblocking reaction for blocked MDI with $\varepsilon$-caprolactam: The blocked MDI was relatively stable due to the high reactivity of MDI. Thus the absorbance peak of NCO group for deblocking reaction appeared slightly under $200^{\circ} \mathrm{C}$. The side reaction of the MDI under high temperature with high reactivity was complex. It considered that the deblocking reaction for blocked MDI was irreversible.

Reaction kinetics of blocked HMDI with $\varepsilon$-caprolactam: The reaction of HMDI deblocked with $\varepsilon$-caprolactam was shown in Fig. 8. The reactivity of HMDI was so low that the stannous octoate was put into experiment as the catalyst, because it was aliphatic isocyanates. The initial concentration of NCO in this reaction system was $\mathrm{C}_{0}=3.9 \times 10^{-3} \mathrm{~mol} \cdot \mathrm{g}^{-1}$. Fig. 9 illustrated that the absorbance peak of NCO at 2274 $\mathrm{cm}^{-1}$ changed with time. The concentration of NCO was figured out at every moment and defined the result of $\left(1 / \mathrm{C}-1 / \mathrm{C}_{0}\right)$ to be as the corresponding figure for time (Fig. 9).

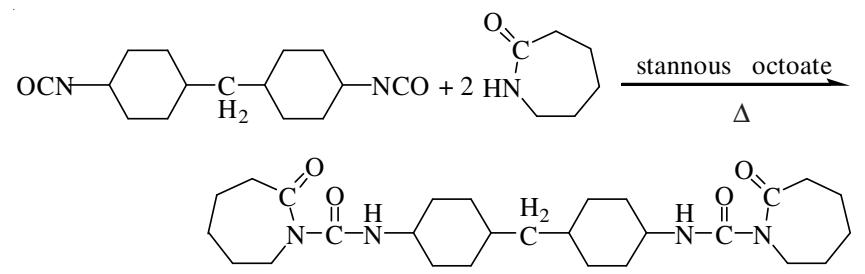

Fig. 8. Scheme of the reaction of HMDI diblocked with CL

The absorbance changed with time at different temperatures for blocked HMDI with $\varepsilon$-caprolactam was shown in Table-2. The absorbance of NCO group continuous became 


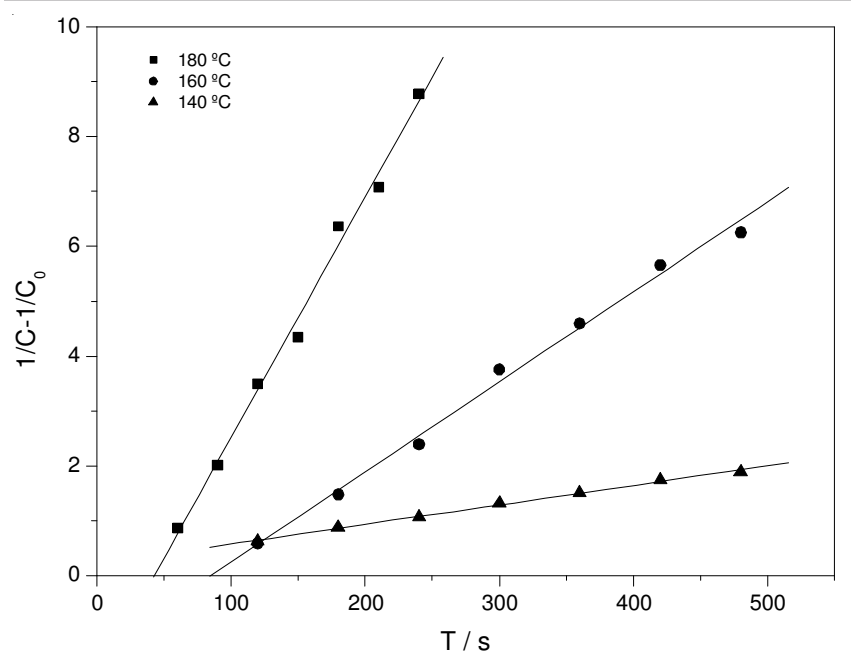

Fig. 9. Plots of $\left(1 / \mathrm{C}-1 / \mathrm{C}_{0}\right)$ against time for blocked HMDI

low, which indicated that the blocking reaction kept proceeding. The reactivity of HMDI was so low that the reaction con dition had to be high temperature. The dimerization and trimerization of isocyanates and isocyanates itself reacting with the blocked isocyanates generated alliphanate or biuret under high temperature, which were thermal decomposition through different kinetics process. Approximately, it considered that the differences for the reaction mainly depend on the differences for the reactivity of the NCO group in the reaction. The second order reaction of initial catalytic blocking reaction of HMDI with $\varepsilon$-caprolactam was testified. The rate constants $\kappa_{3}$ achieved from the straight slope was listed in Table-3.

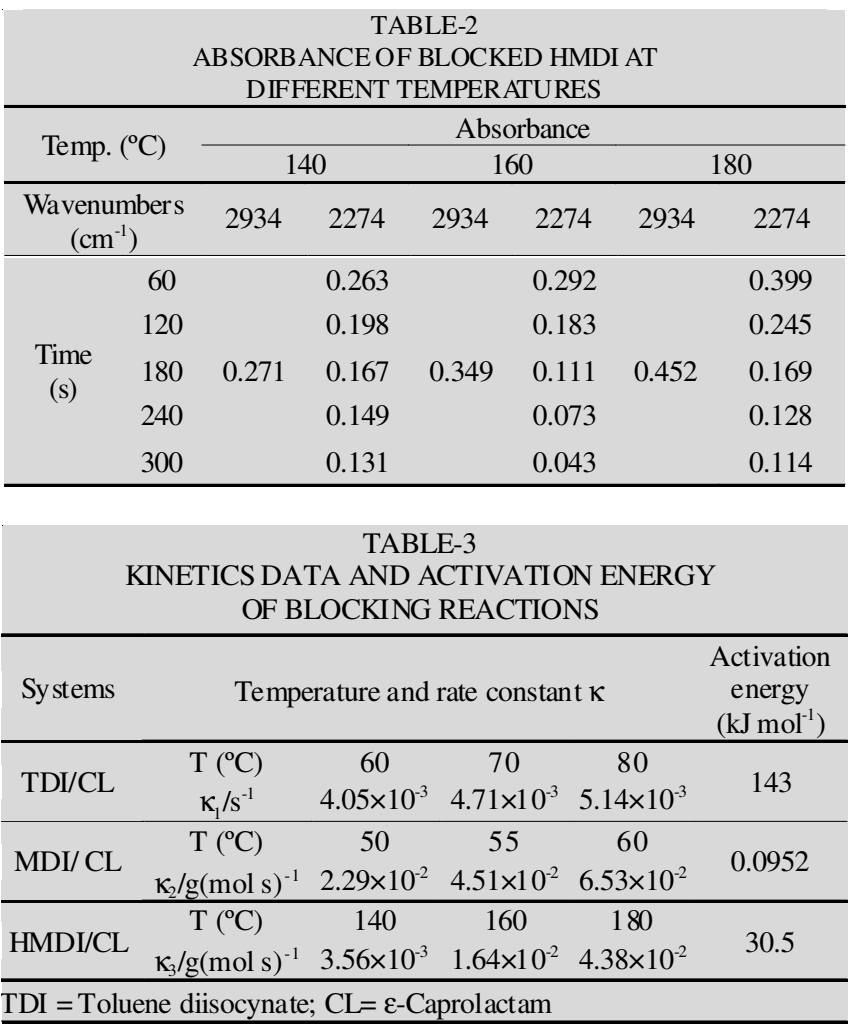

Deblocking reaction for blocked HMDI with $\varepsilon$-caprolactam: The reactivity of HMDI was so low that it only reacted to block at $160^{\circ} \mathrm{C}$ or higher temperature with catalyst. For the deblocking reaction, the temperature should be much higher. There was no absorbance peak of NCO group under $230{ }^{\circ} \mathrm{C}$ in experiment. $\varepsilon$-Caprolactam would have ring-opening reaction if the temperature was too high. Thus the reaction for blocked HMDI with $\varepsilon$-caprolactam was irreversible.

Activation energy of blocked diisocyanate with $\varepsilon$-caprolactam: The experiment was observed by FTIR and analyzed by TGA; the calculation for the blocking reaction was carried on. The constant of reaction rates were listed in Table-3.

According to Arrhenius equation:

$$
\ln \kappa=\ln \mathrm{A}-\mathrm{E}_{\mathrm{a}} / \mathrm{RT}
$$

The reaction rate was converted into logarithm (ln $)$ which was employed to against temperature $(1 / \mathrm{T})$. Then the activation energy $E_{a}$ was acquired shown in Table-3.

\section{Conclusion}

Results showed that the class of blocking reaction for blocked toluene diisocynate with $\varepsilon$-caprolactam was first order, while for MDI and HMDI were both second order. The blocked toluene diisocynate could deblock at $160{ }^{\circ} \mathrm{C}$, the blocking reaction was reversible, while the reactions of MDI and HMDI blocked with $\varepsilon$-caprolactam were irreversible. The activation energy of blocked toluene diisocynate with $\varepsilon$-caprolactam was $143 \mathrm{~kJ} \cdot \mathrm{mol}^{-1}$ and that of blocked MDI and HMDI with $\varepsilon$-caprolactam were 0.0952 and $30.5 \mathrm{~kJ} \cdot \mathrm{mol}^{-1}$ respectively. The reactivity of blocked isocyanates with $\varepsilon$-caprolactam were influenced by both electronic effect and steric effect, which directly reflected by the level of the activation energy. Compared with MDI, the activation energy of blocked toluene diisocynate with $\varepsilon$-caprolactam was higher and the steric hindrance was stronger due to the plenty of groups of toluene diisocynate. Compared with HMDI, the activation energy of MDI was lower because of the electron-withdrawing tendency for aromatics than aliphatics.

\section{ACKNOWLEDGEMENTS}

This work was financially supported by the Natural Science Foundation of China (No. 21171004) and the Natural Science Foundation of Anhui Province Education Department (KJ2011A064, KJ2011A070).

\section{REFERENCES}

1. D.A. Wicks and Z.W. Wicks Jr., Prog. Org. Coat., 41, 1 (2001).

2. Z.W. Wicks Jr., D.A. Wicks and J.W. Rosthauser, Prog. Org. Coat., 44, 161 (2002).

3. D.A. Wicks and Z.W. Wicks Jr., Prog. Org. Coat., 43, 131 (2001).

4. F.N. Jones, V. Swarup, A.I. Yezrielev and R.A. Subrayan, US Patent 6103826 (2000).

5. L.A. Flood, R.B. Gupta, T. Iyengar, D.A. Ley and V.K. Pai, US Patent 6063922 (2000).

6. C. Wang and Q.P. Yuan, J. Beijing Univ. Chem. Technol., 34, 432 (2007).

7. X.W. Wang and Z.F. Zhou, Acta Phys.-Chim. Sin., 25, 2181 (2009).

8. P.F. Yang and Y.D. Han, Chinese Chem. Lett., 21, 853 (2010),

9. G. Sankar and A.S. Nasar, J. Appl. Polym. Sci., 109, 68 (2008).

10. G. Sankar and A.S. Nasar, Eur. Polym. J., 45, 911 (2008). 